\title{
Solar Hot Water Heating System Analysis Using Different Software in Single Family House
}

\author{
Rasa Džiugaitė-Tumėnienè, Giedrè Streckienè \\ Department of Building Energetics, Faculty of Environmental Engineering, Vilnius Gediminas Technical University, \\ Sauletekio av. 11, Vilnius 10223, Lithuania
}

\begin{abstract}
Nowadays the main challenges and principles to increase energy efficiency in the buildings sector are: a very high energy performance of buildings, a significant extent of renewable energy sources and a minimum use of fossil fuels. Therefore, a wide variety of the software is used to analyze the building energy performance, integration of renewable energy into various energy systems. This paper presents the comparison of simulation results generated by TRNSYS, Polysun and energyPRO software. These applications have been used for the analysis of a solar water heating system for the domestic hot water (DHW) preparation. A single family individual house, located in the cold climate, has been chosen as a case study. The building energy demand for the DHW preparation has been analyzed. The results show differences in total annual and monthly solar fraction for the DHW coverage, the heat losses of a storage tank and the energy demand from an auxiliary heat source. This study presents that simulation results using TRNSYS and Polysun can be considered as more reliable that results of energyPRO simulation.
\end{abstract}

Keywords: solar water heating system; simulation; TRNSYS; PolySun; energyPRO.

\begin{tabular}{|ll|}
\hline \multicolumn{2}{|c|}{ Nomenclature } \\
$a_{1} \quad$ linear loss coefficient for flat-plate collectors, $\mathrm{W} / \mathrm{m}^{2} \mathrm{~K}$ \\
$a_{2}$ & quadratic loss coefficient for flat-plate collectors, $\mathrm{W} /\left(\mathrm{m}^{2} \mathrm{~K}\right)^{2}$ \\
$\eta_{0} \quad$ optical efficiency factor \\
Abbreviations \\
DHW $\quad$ domestic hot water \\
IAM & incident angle modifier \\
NZEBs & net zero energy buildings \\
SC & solar collector \\
SCHX & solar collector heat exchanger \\
SWH & solar water heating \\
\hline
\end{tabular}

\section{Introduction}

In developed countries, energy consumption in the building sector represents a major part of the total energy budget. In the European Union this is approximately equal to $40 \%$ of the total energy consumption. A considerable percentage of this amount is spent for hot water production. One way to reduce this amount of energy is to employ solar energy [1].

Solar water heaters are the most popular means to use solar energy because of technological feasibility, low temperature operating conditions and economic attractions in comparison with other kinds of solar energy utilization. This technology has been well developed and can be easily implemented [2-3]. However, the cost of solar energy systems needs to be reduced in order to make thermal collectors competitive in cold climate countries [4].

Solar water heating (SWH) technologies have been the subject of many investigations. Biaou and Bernier examined various means of producing domestic hot water (DHW) with renewable energy in net zero energy buildings (NZEBs). Their results showed that heating DHW with thermal solar collectors with an electric backup is the best solution for analyzed building [5]. The simplified procedure of considerable interest when assessing the energy feasibility of a solar system with

Corresponding author: Rasa Džiugaitè-Tumėnienė. E-mail address: rasa.dziugaite-tumeniene@vgtu.lt

http://dx.doi.org/10.3846/enviro.2014.258

(C) 2014 The Authors. Published by VGTU Press. This is an open-access article distributed under the terms of the Creative Commons Attribution License, which permits unrestricted use, distribution, and reproduction in any medium, provided the original author and source are credited. 
reference to other solar conversion technologies was proposed by Raffenel et al. [6]. Their analysis showed that proposed procedure requires a good deal of data on the solar system and also a well skilled designer; the required data are not always known and greatly affect the system performance in the energy simulation. The potential for using solar technologies and thermal energy storage technologies in a region of Northern Europe (Welsh housing) was made by Ampatzi et al. [7]. It was revealed that for most cases, if reasonable sized stores would be used (up to $300 \mathrm{kWh}$ thermal energy storage capacity) then the solar contribution to the overall thermal consumption, in the most favorable conditions, would be around $42-58 \%$. The optimized system can fulfil $83-97 \%$ of the DHW demand during May to September [8]. A daily averaging sizing method of solar combi-systems was proposed by Lund (2005) and compared with the results of the TRNSYS software. The method was used to analyze the economic trade-off between collector area and heat storage volume coming to the result that it is not economically rentable to increase the size of the heat storage much beyond the daily capacity [9].

Solar energy is characterized by a great variability in time, it is necessary to perform detailed transient analyses. Such analyses require the input of a great number of parameters, whose value can sometimes hardly to be determined and that are not at the disposal of the designer during the initial design phases of a system. As a result they are set to the default values suggested by software manuals. It is well known that it is in the initial design phases that decisions will affect the performance of a system [6]. Different computational tools have been developed to evaluate the long-term performance of solar systems and the effect of design parameters. However, when beginning an investigation into the potential of solar energy use, it is difficult to identify which energy tool is better suitable for the investigation $[8,10]$. It is eventually the modeller's decision in level of modelling complexity that determine whether the simulated environment is representative or no of a particular case [11].

The present work is focused on using three different computational tools (TRNSYS, PolySun and energyPRO) to analyze a forced circulation solar DHW heating system for a single family detached house in Vilnius in Lithuania. The paper contains an individual description about each of the software and application of it for a case study. The present study determines that the main differences of simulations results of the SWH system occur during the evaluation of the thermal efficiency of solar collectors, energy out of the auxiliary heater and heat losses of the pipes and the storage tank. The overestimation of the performance of the SWH heating system can lead to an incorrect size of the solar collectors, the auxiliary heat source and the storage tank in the early design stage of the energy system of the building.

\section{The overview of selected software}

\subsection{TRNSYS}

TRNSYS is a transient systems simulation program that has been commercially available since 1975 [12]. This software has been used extensively to simulate solar energy applications, conventional buildings, and even biological processes [8, 10, 13-14]. The software has a modular structure with a main visual interface. Users simulate complex systems in TRNSYS by selecting system components and linking together their inputs and outputs.

There have been several studies that used TRNSYS to evaluate the effect of different design parameters and operation conditions on the performance of thermosyphon SWH system and forced circulation systems $[2,7-8,15]$. TRNSYS also can be used for an analysis of a single component or physical phenomena in the SWH system, for example, thermal stratification in storage tank [15-18]. In this work, TRNSYS simulation tool is chosen due to the wide spread of this tool in the field of energy simulation, the wide variety of validated and published results in the field of energy simulation. Therefore, TRNSYS was selected as the main program and its results were compared to other simulation tools' generated results.

\subsection{Polysun}

The Polysun program performs the dynamic annual simulations of solar energy systems and helps to optimize them [19]. The program is user friendly and the graphical user interface permits comfortable and clear input of all system parameters. All aspects of the simulation are based on physical models that work without empirical correlation term [20]. The input of the required data is very easy and done in a ready-made graphical environment [20]. In addition, the program performs economic viability analysis and ecological balance, which includes emissions from the eight most significant greenhouse gasses, thus the emissions of systems working only with conventional fuel and systems employing solar energy can be compared. Program Polysun was validated by Gantner (2000) and was found to be accurate to within 5-10\% [21]. Considering a mean simulation time of 1 minute for a one-year simulation, the software Polysun is chosen to perform the analysis of solar energy system.

\section{3. energyPRO}

The energyPRO tool is a complete modeling software package for combined techno-economic design, analysis, and optimization of cogeneration, trigeneration projects as well as wind power and solar energy projects [22]. It is developed and maintained by the company EMD International $\mathrm{A} / \mathrm{S}$ in Denmark. It can model all types of thermal generation except nuclear, all renewable generation, and all energy storage units to complete the analysis. The analysis is carried out using a 
one-minute time-step for a maximum duration of 40 years [10, 23]. Normally, energyPRO is used to model particular energy projects, but it can be used also in different manner, for example, it is possible to model the heat demand from a group of NZEBs with solar energy production and connect the group of NZEBs to a district heating grid [24]. This software also was used to analyze the preparation of DHW in a multi-storey building using solar energy [25]. The applications of this tool of other authors show that the customization level of energyPRO is low and rough simulation results are obtained. However, comparing energyPRO with other analysed tools, energyPRO provides the possibility to create a simulation model quicker (less time-consuming).

\section{Case study and main assumptions}

\subsection{Hot water load profile}

The case study presents a typical single family detached house with two adults and two children. The energy demand for hot water preparation is $3825 \mathrm{kWh} / \mathrm{a}$. The average DHW consumption is 50 liters per person per day. Therefore, the SWH system is designed to provide $200 \mathrm{l}$ of hot water per day at $55^{\circ} \mathrm{C}$ for the single family detached house.

The hourly distribution of DHW consumption during a day is affected by several factors. Usually, it varies from day to day, from season to season and from family to family. Different cyclic load profiles such as Rand, constant, early morning, early afternoon, late morning, or late afternoon have been considered and studied in the literature [8, 26-28]. The daily load profile of the system examined in this study is shown in the Figure 1. This profile is used in accordance with a typical hot water usage model [26]. Monthly average inlet water temperature is a function of outdoor ambient air and main supply water intake temperatures. However, an average temperature of cold water is assumed to be $10^{\circ} \mathrm{C}$ and it is constant parameter in all simulations.

\subsection{System configuration}

The system consists of solar thermal energy collectors, a circulation pump, a storage tank, an auxiliary heat source, shut-off and control valves, differential temperature controller. Main characteristics of used flat-plate collector by all simulation tools were taken from test report: KTB Nr. 2006-30-en made by Fraunhofer Institute for Solar energy Systems [29]. The main components of the system are shown in the Figure 2 and described below.

As can be seen from Figure 2, the heat for DHW preparation is supplied by the $7.21 \mathrm{~m}^{2}$ of flat-plate solar collectors and the additional heat source with the heating capacity of $5.0 \mathrm{~kW}$. Three units of solar collectors make one array. The total gross area of solar collectors has been foreseen in order to achieve approximately $100 \%$ coverage of the heat demand during June to August. An orientation of the solar collectors is to the south. A tilt angle of $45^{\circ}$ and the storage tank of $0.3 \mathrm{~m}^{3}$ are assumed. The circulation pump of $32 \mathrm{~W}$ is foreseen. The specific flow rate in the solar collector loop is $40 \mathrm{l} / \mathrm{h} / \mathrm{m}^{2}$.

Pipe losses of solar collector (SC) system and storage tank losses are taken into account in the case study. The piping of the SC loop is made from seamless copper, the diameter is $22 \times 1.2 \mathrm{~mm}$ and insulated with the thermal insulation of $25 \mathrm{~mm}$. The length of outdoor piping is $15 \mathrm{~m}$ and the length of indoor piping is $15 \mathrm{~m}$.

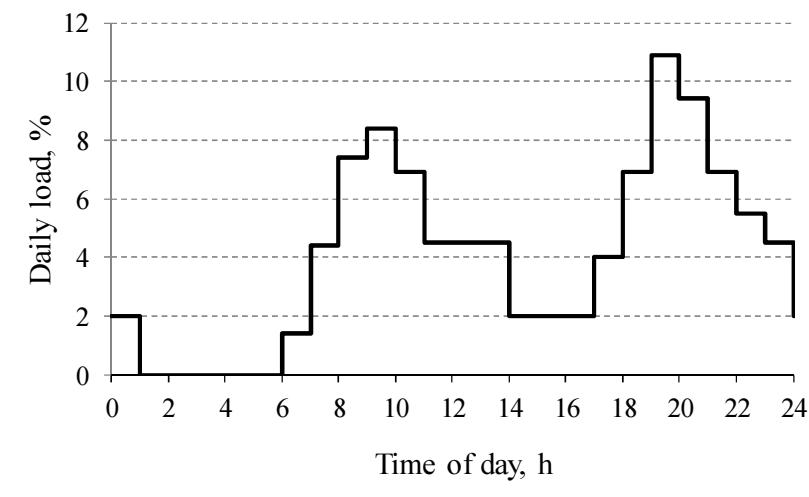

Fig. 1. Daily hot water consumption pattern

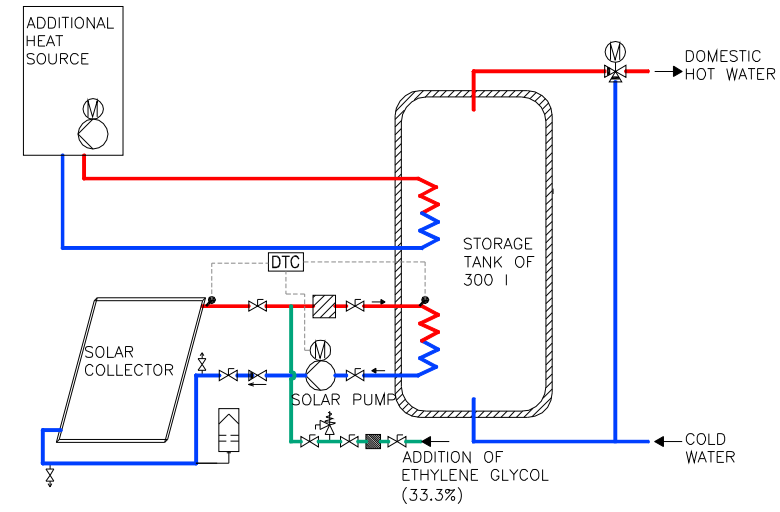

Fig. 2. The hydraulic scheme of solar hot water heating system

Differential temperature controller is used to control the solar thermal system. The controller with two temperature sensors controls the circulating pump of solar loop. One of the sensors is located at the top side of the SC array and measures the outflow temperature of the collector. The second sensor is located at the upper side of coil heat exchanger of the collectors in the storage tank (layer $3^{\text {th }}$ from the storage bottom). The controller monitors the temperature difference between the solar collectors and the storage tank. Therefore, the main assumptions have been made for the operation of the solar pump. The controller switches the circulating pump on, when the temperature difference is $5{ }^{\circ} \mathrm{C}$, and stops the pump, when the temperature of the solar collectors drops to $2{ }^{\circ} \mathrm{C}$ above the storage temperature. 
Another controller is used to control the additional heat source. The controller with two temperature sensors controls the auxiliary heater. One of the sensors is foreseen on the hot water end-user side. The second sensor is located at the upper side of coil heat exchanger of the additional heater in the storage tank (layer $7^{\text {th }}$ counting from the storage bottom). The controller monitors the temperature difference between the hot water end-user and the storage tank. Therefore, the controller switches the additional heater on, when the temperature difference is $0{ }^{\circ} \mathrm{C}$, and stops the heater, when the temperature rises up to $10^{\circ} \mathrm{C}$. The minimum operation time of the additional heater of $10 \mathrm{~min}$ and the minimum downtime of 0 min are assumed in the simulations.

During the simulations the indoor temperature of the technical room has been set as $18^{\circ} \mathrm{C}$.

\subsection{Weather data}

Calculations are made for one year using meteorological data of Vilnius city. The weather data generator Meteonorm [30] is included as an integral part of Polysun. Meteonorm produces a typical weather profile for a user-defined location interpolating between location data supplied from weather stations and satellites. The same values of ambient temperature, global and diffuse irradiation are used for all simulations. These weather parameters are shown in the Figure 3.

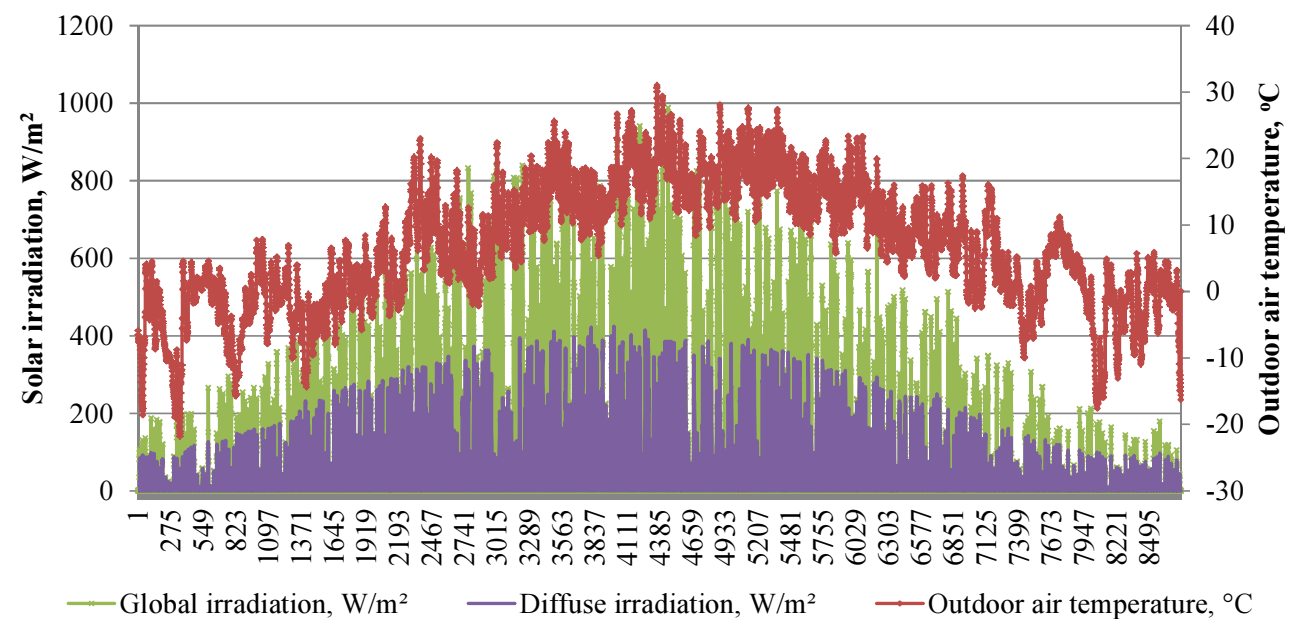

Fig. 3. Weather data of Vilnius for simulation of SWH system

The average annual outdoor air temperature is $6.8{ }^{\circ} \mathrm{C}$, the highest air temperature $\left(31.0{ }^{\circ} \mathrm{C}\right)$ is reached in July, the lowest temperature $\left(-21.9^{\circ} \mathrm{C}\right)$ in January, respectively. Positive average monthly outdoor air temperature values are from April till November (from $1.5^{\circ} \mathrm{C}$ till $18.4^{\circ} \mathrm{C}$ ). All winter and March the average monthly outdoor air temperature is negative (from $4.1{ }^{\circ} \mathrm{C}$ till $\left.-0.05{ }^{\circ} \mathrm{C}\right)$. The highest average monthly global irradiation value $\left(988.3 \mathrm{~W} / \mathrm{m}^{2}\right)$ is achieved also in July, the lowest average monthly value $\left(178.9 \mathrm{~W} / \mathrm{m}^{2}\right)$ is in December. The annual global irradiation is $1000.6 \mathrm{kWh} / \mathrm{m}^{2}$, diffuse irradiation is $528.4 \mathrm{kWh} / \mathrm{m}^{2}$ in Vilnius, respectively. However, the use of the monthly data of solar radiation is not suitable for the detailed assessment of solar DHW system performance. Therefore, all simulations were executed using hourly weather data values.

\subsection{System models in different software}

The case study is focused on the simulations of solar DHW heating system using TRNSYS, Polysun and energyPRO computer tools. The main components of the system have been added to the simulations programs. The model of the solar DHW heating system, made using TRNSYS, is shown in the Figure 4.

Type 1c was used for SC simulation. It models a quadratic efficiency that is a generalization from the well-known HottelWhillier equation. This Type is recommended when SC test reports according to ASHRAE or European standards are available.

The models of the solar DHW heating system, made using Polysun and energyPRO, are shown in the Figure 5 and Figure 6, respectively. As can be seen from Figure 4, 5, 6, the most complex model is described by TRNSYS. The main technical and operational parameters of the flat plate SC and storage tank, added to the different simulation tools, are presented in Table 1. 


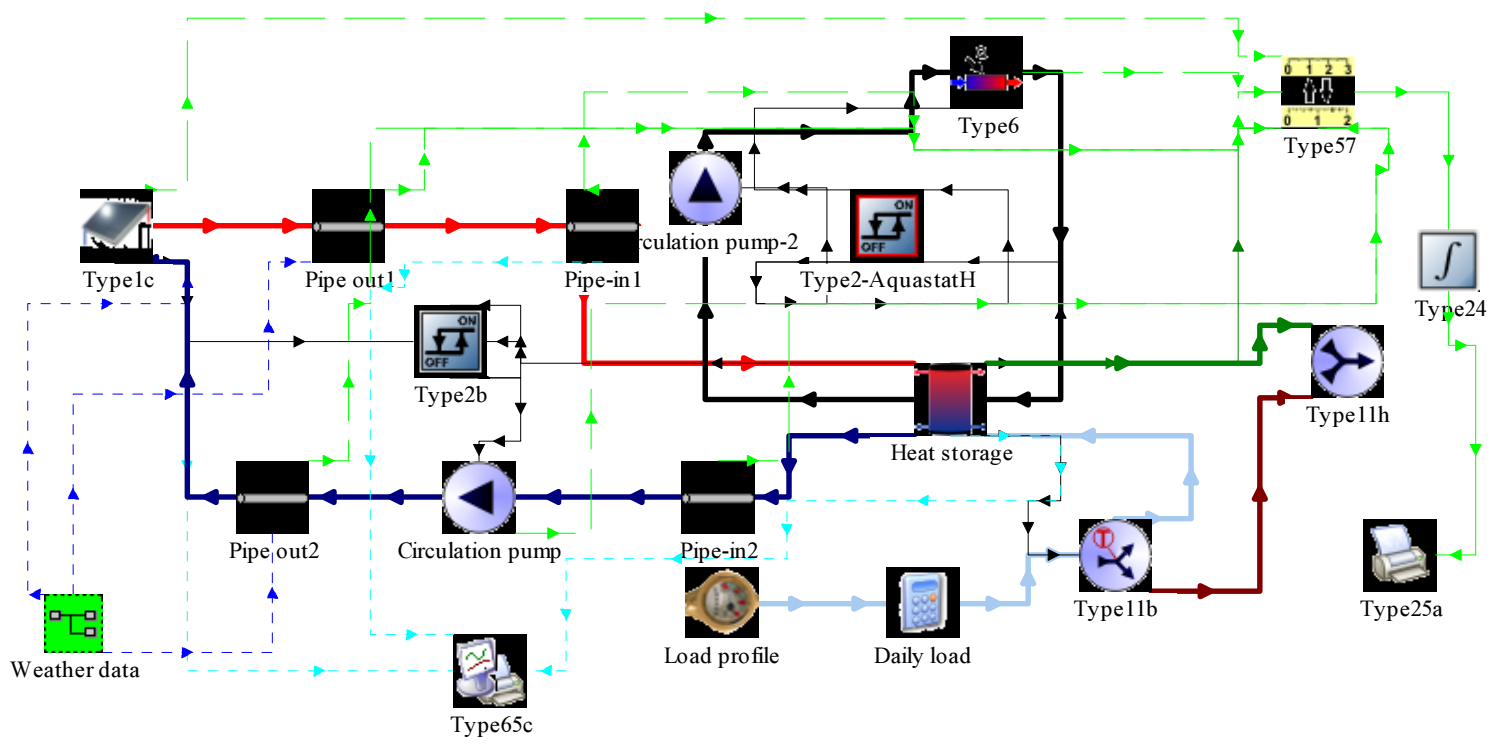

Fig. 4. The model of solar DHW heating system in TRNSYS

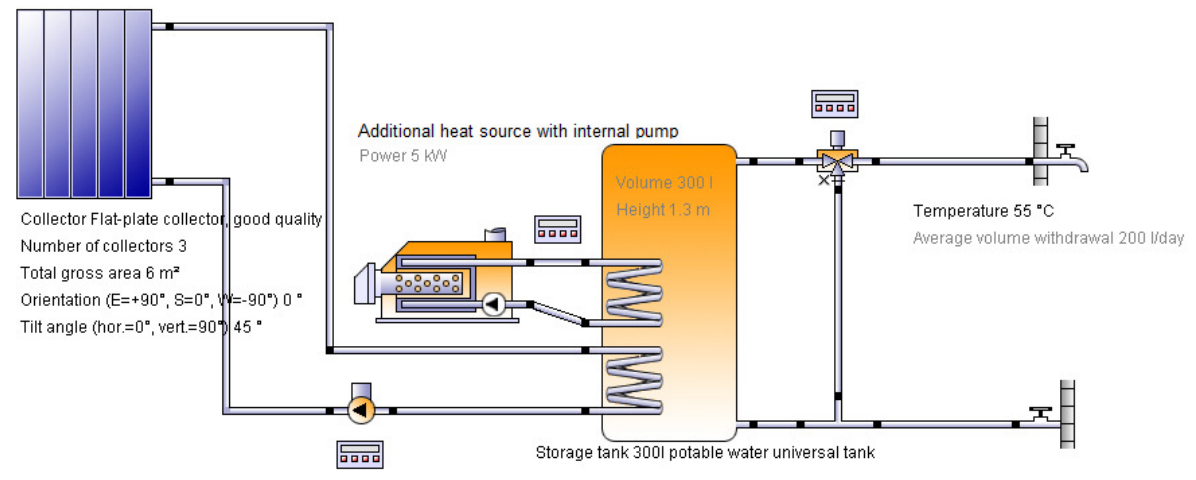

Fig. 5. The model of solar DHW heating system in Polysun

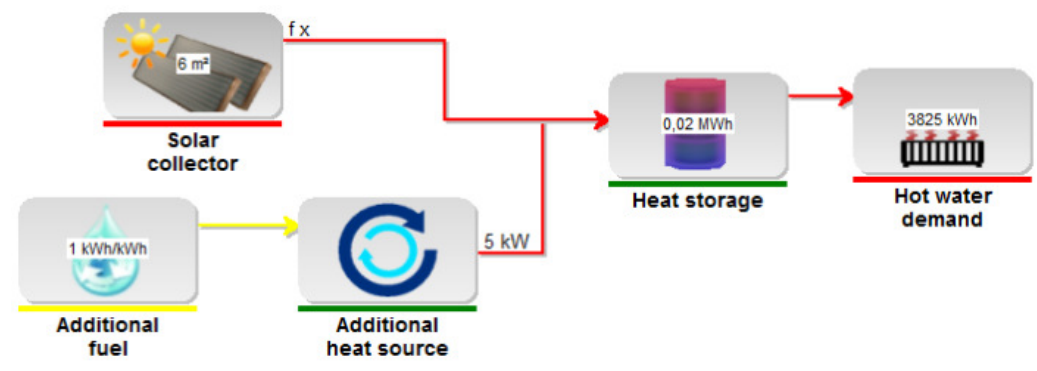

Fig. 6. The model of solar DHW heating system in energyPRO

TRNSYS and Polysun models take into account the thermal stratification in the storage tank. The interior of the tank is subdivided into twelve isothermal layers in both simulation tools. However, the energyPRO model has limitations to evaluate this phenomenon and no stratifications effects are evaluated here. Describing the storage tank, Polysun takes into account the construction and insulation materials in detail. TRNSYS uses heat loss coefficients $\left(\mathrm{W} / \mathrm{m}^{2} \mathrm{~K}\right)$ in each layer. These coefficients should be calculated by evaluating the construction of the tank. energyPRO allows to evaluate only insulation thermal conductivity that is the same for all surface area of the storage tank.

energyPRO calculates collector area as the integer number, so for the further calculations $6 \mathrm{~m}^{2}$ was used. There is no possibility to use another heat transfer medium as water in any loop in the energyPRO model. Whereas, TRNSYS allows describing any material by its physical and thermal characteristics (e.g. fluid specific heat, density thermal conductivity, viscosity etc.). TRNSYS and Polysun calculate heat losses in pipes in detail (pipe diameters, materials, flow rates, temperatures). energyPRO evaluates these losses in collector field only in percentage of production. 
Table 1. Input characteristics used for the simulation of flat-plate solar collectors and storage tank depending on the simulation tool

\begin{tabular}{|c|c|c|c|c|c|c|c|}
\hline $\begin{array}{l}\text { Parameter/Input of } \\
\text { solar collectors }\end{array}$ & TRNSYS & PolySun & energyPRO & $\begin{array}{l}\text { Parameter/Input of } \\
\text { storage tank }\end{array}$ & TRNSYS & PolySun & energyPRO \\
\hline Total gross area, $\mathrm{m}^{2}$ & - & 7.21 & - & Volume, 1 & 300 & 300 & 300 \\
\hline $\begin{array}{l}\text { Total aperture area } \\
\text { (required in case of } \\
\text { specific flow rate), } \mathrm{m}^{2}\end{array}$ & 6.27 & 6.27 & 6 & Height, m & 1.3 & 1.3 & 1.3 \\
\hline Total absorber area, $\mathrm{m}^{2}$ & - & 6.29 & - & Bulge height, $\mathrm{mm}$ & - & 100 & - \\
\hline $\begin{array}{l}\text { Wind speed at the } \\
\text { collector array, } \%\end{array}$ & $\begin{array}{l}\text { According to } \\
\text { Polysun } \\
\text { weather data }\end{array}$ & 50 & - & Material & - & Stainless steel & - \\
\hline$\eta_{0}($ laminar, turbulent) & 0.848 & 0.848 & 0.848 & Wall thickness, mm & - & 2.5 & - \\
\hline$a_{l}, \mathrm{~W} / \mathrm{m}^{2} / \mathrm{K}$ & 4.021 & 4.021 & 4.021 & Insulation & $0.04 \mathrm{~W} / \mathrm{mK}$ & Rigid PU foam & $0.04 \mathrm{~W} / \mathrm{mK}$ \\
\hline$a_{2}, \mathrm{~W} /\left(\mathrm{m}^{2} / \mathrm{K}\right)^{2}$ & 0.0108 & 0.0108 & 0.0108 & $\begin{array}{l}\text { Thickness of } \\
\text { insulation, } \mathrm{mm}\end{array}$ & 80 & 80 & 80 \\
\hline Heat transfer medium & $\begin{array}{l}\text { Mixture of } \\
\text { water and } \\
33.3 \% \text { ethylene }\end{array}$ & $\begin{array}{l}\text { Mixture of } \\
\text { water and } \\
33.3 \% \text { ethylene }\end{array}$ & Water & $\begin{array}{l}\text { Thickness at top of } \\
\text { tank }\end{array}$ & 80 & 80 & 80 \\
\hline IAM evaluation & $\mathrm{K}_{\theta}=0.095$ at $50^{\circ}$ & $\mathrm{K}_{\theta}=0.095$ at $50^{\circ}$ & $\begin{array}{l}\mathrm{K}_{\theta}=0.095 \text { at } \\
50^{\circ}\end{array}$ & Thickness at tank base & 50 & 50 & 80 \\
\hline
\end{tabular}

\section{Results and discussion}

In this section, the simulation results of performance of solar DHW system are investigated. The monthly results of heat losses of the storage tank, produced energy from the auxiliary heat source and SC field yield are shown in the Figure 7.

As can be seen from Figure 7, the solar collector system can give approximately $2427 \mathrm{kWh} / \mathrm{a}$ of thermal energy to the system. The values of SC field yield simulated with TRNSYS, Polysun and energyPRO do not differ significantly. The result of Polysun gives 5.2\% higher annual solar thermal output compared to the result of TRNSYS and $0.3 \%$ higher compared to the result of energyPRO. The differences between the values of produced solar thermal energy occur due to the monthly variations of the efficiency of the solar thermal system.

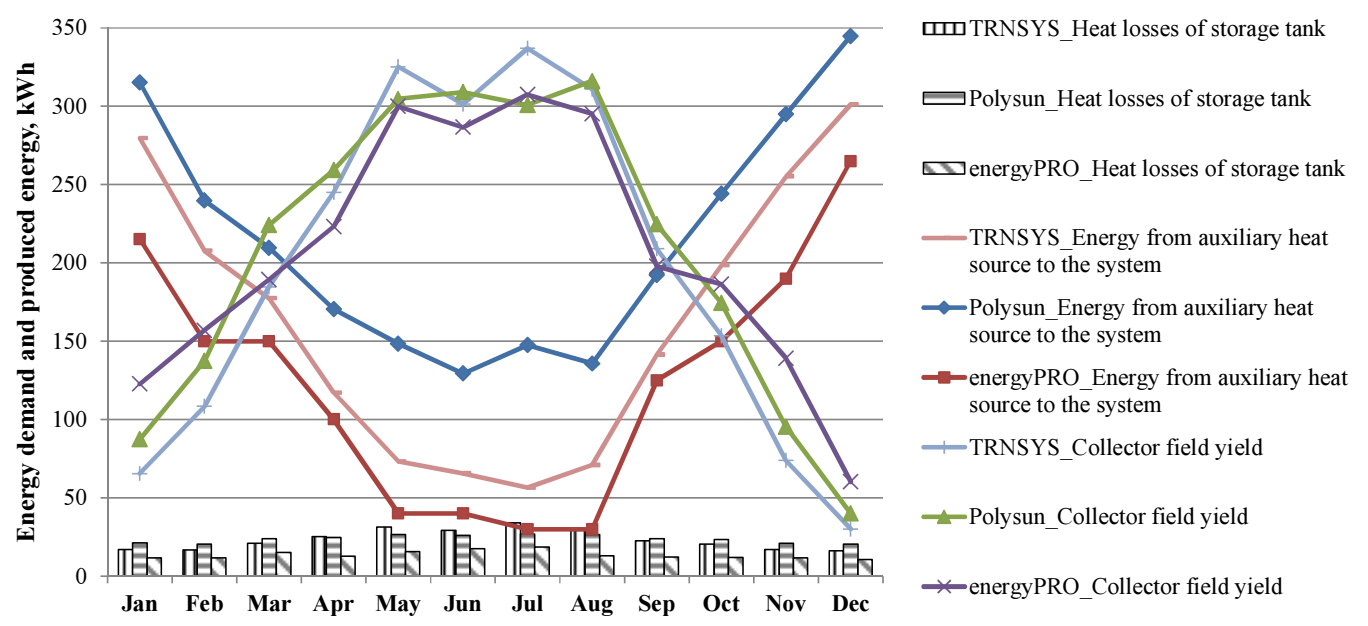

Fig. 7. Energy demand and produced energy of SC system

The monthly efficiency of SC system is defined as the ratio of the solar thermal energy used to the system and solar energy received on the collectors. The solar irradiation on the SC aperture consists of direct and diffuse radiation. The results of simulations show that the annual solar irradiation onto SC area of $1 \mathrm{~m}^{2}$ is $1126.4 \mathrm{kWh} / \mathrm{m}^{2}$. The output of TRNSYS indicates that the efficiency of the SC system varies in a range of $31 \%$ and $35 \%$ from April to October and during winter time it reduces to $25 \%$. The similar values are simulated with Polysun. During intermediate and summer time the efficiency of SWH system varies from $30 \%$ to $36 \%$. However, the average SC efficiency value of $33 \%$ remains in cold period. The misleading values of the monthly efficiency of SC system were obtained using energyPRO. The results show that the monthly efficiency of SC system varies in the range of $29 \%$ and 33\% from April to October, accordingly, from $28 \%$ to $39 \%$ during intermediate and from $37 \%$ to $51 \%$ during winter time. Since the output of energyPRO is limited, therefore, more detailed analysis of the performance of SC system is not available. 
Considering the monthly solar fraction of solar thermal energy to the system, the SC system is able to cover from $81 \%$ to $86 \%$ of the DHW demand from May to August according to the results of TRNSYS. The results of Polysun show that the solar fraction is from $67.3 \%$ to $70.5 \%$. The highest values of the solar fraction are simulated by energyPRO, that are from $88 \%$ to $91 \%$. The difference of the simulated results can be due to the different behavior of differential temperature controller or due to the use of various mathematical models integrated in the tools.

The comparison of the monthly solar fraction of different simulations shows the different monthly performance of the auxiliary heater. The result of Polysun gives $24.4 \%$ higher annual energy output of auxiliary heater compared to the result of TRNSYS and $42.3 \%$ higher compared to the result of energyPRO. The main difference between the simulated values occurs due to the total energy demand, required for DHW preparation and to cover heat losses of pipes, storage tank and connection losses of storage tank. Connection losses of storage tank mean the heat losses from the connections of pipes, installed in the tank. Only Polysun evaluates the connection losses of storage tank, therefore more energy is required to produce.

The comparison of monthly heat losses of storage tank are presented in this case study. The result of Polysun gives $1.9 \%$ higher annual heat losses of storage tank compared to the result of TRNSYS and $42.8 \%$ higher compared to the result of energyPRO. Considering too high value of heat losses of storage tank, resulted by energyPRO, more detailed output data is necessary in order to identify the issue. The higher losses of storage tank can be due to the higher temperatures supplied to the storage tank. However, energyPRO is limited in this respect. Therefore, concluding these results of simulations, the main influencing factor of the differences can be the different mathematical models integrated in the tools.

One of the main parameters of the performance of the solar thermal system such as the outflow temperature of solar collectors, the temperatures of the heat-transfer medium at upper and lower connections of the heat exchanger of the SC system are shown in the Figure 8.
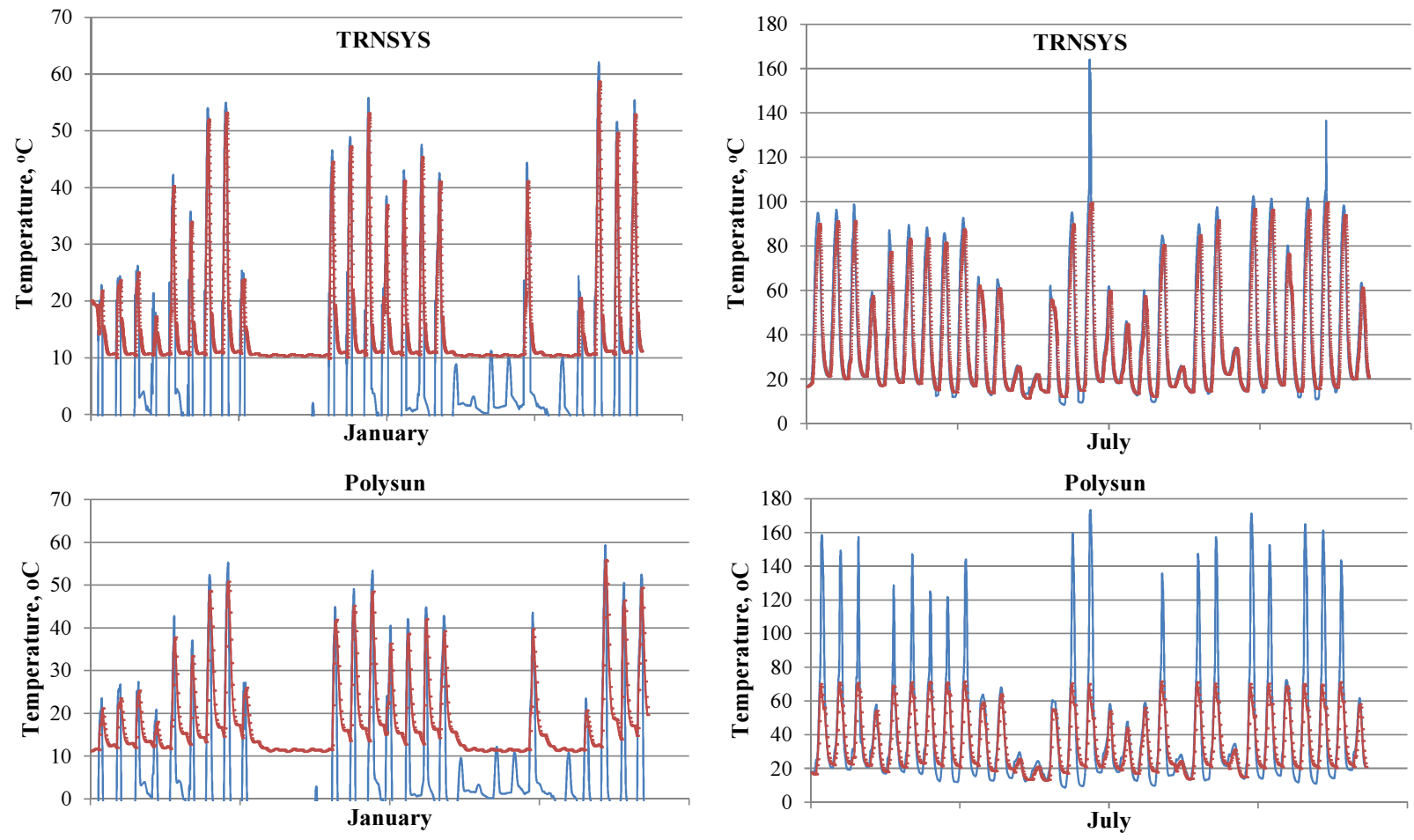

— SC outflow temperature —-Temperature at lower connection of SCHX

Fig. 8. Temperatures of heat-transfer medium of SC system

As can be seen from the Figure 8, the performance of the SWH system, simulated by TRNSYS, is similar compared to the simulated by Polysun. However, the higher temperatures of the heat-transfer medium, simulated with Polysun, have been noticed in the SC system. During the coldest month the average temperature at the upper connection of the solar collector heat exchanger (SCHX) is $26.9^{\circ} \mathrm{C}$ and at the lower connection of SCHX is $17.7^{\circ} \mathrm{C}$. During the warmest month the average temperature at the upper connection of SCHX is $47.2^{\circ} \mathrm{C}$ and at the lower connection of SCHX is $34.4^{\circ} \mathrm{C}$. The results simulated with TRNSYS, show, that the average temperature at the upper connection of $\mathrm{SCHX}$ is $20^{\circ} \mathrm{C}$ and at the lower connection of SCHX is $14.6{ }^{\circ} \mathrm{C}$ on January. Respectively, the temperature of $38.2{ }^{\circ} \mathrm{C}$ is at the upper connection of SCHX and $36.5^{\circ} \mathrm{C}$ at the lower connection of SCHX in June. On the one hand the better performance of the SWH system is simulated with Polysun, on the other hand it can be noticed that the solar collectors reach the maximum achievable collector temperature up to $177^{\circ} \mathrm{C}$. The duration of the stagnation conditions is $2.6 \%$ of all system operation time, while the results of TRNSYS have shown that only few times the solar collectors reach the temperature of $164{ }^{\circ} \mathrm{C}$. 
Considering the water temperatures in the storage tank, the average monthly water temperature is analyzed and shown in the Figure 9.

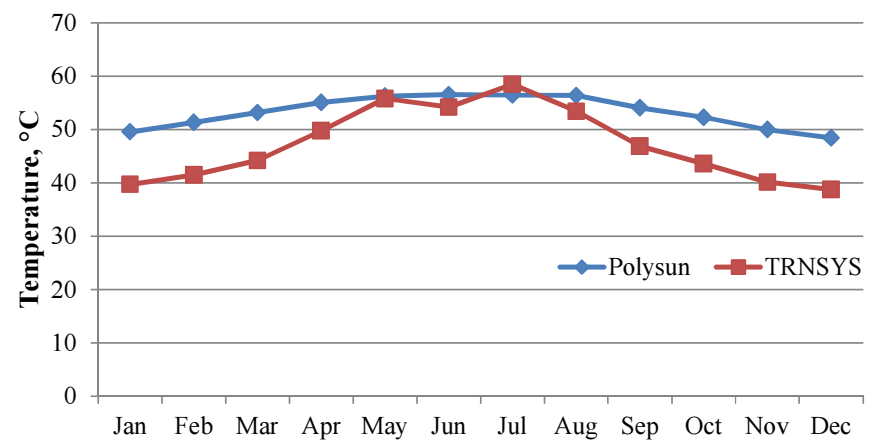

Fig. 9. An average water temperature in storage tank

As can be seen from the Figure 9, the results of Polysun presented that the average monthly water temperature in storage tank is maintained almost constant and it varies from $49.6{ }^{\circ} \mathrm{C}$ to $56.5^{\circ} \mathrm{C}$ during the year. The results of TRNSYS show that the water temperature is reduced up to $38.7^{\circ} \mathrm{C}$ in December and increased up to $58.5^{\circ} \mathrm{C}$ in July. Comparing these results, the auxiliary heater has been operated more frequently in order to maintain the constant water temperature in storage tank in the case of Polysun.

The heat losses of pipes and energy required by the circulation pump of the SC system have been considered in this study. The simulation results are shown in the Figure 10.
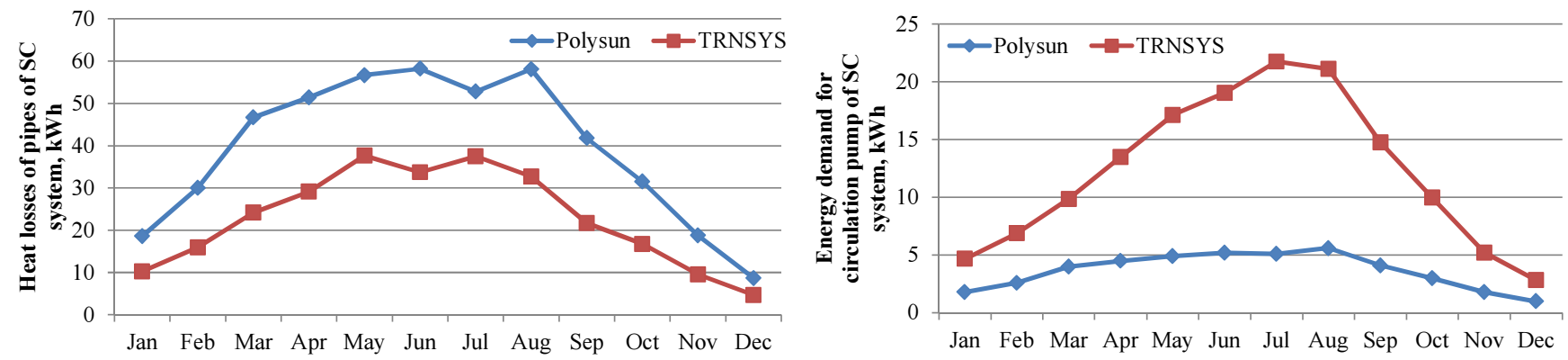

Fig. 10. Heat losses of pipes and energy demand for circulation pump of SC system

As can be seen from the Figure 10, the heat losses of pipes simulated by Polysun are $42 \%$ higher comparing to the results of TRNSYS. This difference appears due to the higher temperatures of heat-transfer medium in the SWH loop in case of Polysun. Considering the energy demand for the circulation pump of the SC system, the value of TRNSYS is 70\% higher comparing to the results of Polysun. The main difference of the values is due to the control of the circulation pumps.

The simulations results indicate that the annual thermal efficiency of the flat-plate solar collectors varies from $30 \%$ to $36 \%$ and are in agreement with the results that are presented by other authors [31, 32].

\section{Conclusions}

Considering the use of TRNSYS, Polysun and energyPRO software for the analysis of solar DHW heating system of single family house in cold climate, the following conclusions can be deduced:

- The result of Polysun gives 5.2\% higher annual solar thermal output compared to the result of TRNSYS and $0.3 \%$ higher compared to the result of energyPRO.

- The result of Polysun gives $24.4 \%$ higher annual energy output of auxiliary heater compared to the result of TRNSYS and $42.3 \%$ higher compared to the result of energyPRO.

- The result of Polysun gives 1.9\% higher annual heat losses of storage tank compared to the result of TRNSYS and $42.8 \%$ higher compared to the result of energyPRO. The heat losses of pipes simulated by Polysun are $42 \%$ higher comparing to the results of TRNSYS.

- The study presents that the results of simulations using TRNSYS and Polysun can be considered as more reliable than the results of energyPRO. However, in order to get more reliable comparison of the results of the simulations using TRNSYS and Polysun, the experimental evaluation of the solar hot water heating system of single family house has to be performed. 


\section{Acknowledgement}

This research was funded by a grant (No. ATE-03/2012) from the Research Council of Lithuania. The authors also want to express their appreciation to Laboratory of Building and Microclimate Systems, Vilnius Gediminas Technical University.

\section{References}

[1] Kalogirou, S. 2009. Thermal Performance, Economic and Environmental Life Cycle Analysis of Thermosiphon Solar Water Heaters, Solar energy 83(1): 39-48. http://dx.doi.org/10.1016/j.solener.2008.06.005

[2] Ayompe, L. M.; Duffy, A.; McCormack, S. J.; Conlon, M. 2011. Validated TRNSYS model for forced circulation solar water heating systems with flat plate and heat pipe evacuated tube collectors, Applied Thermal Engineering 31(8-9): 1536-42. http://dx.doi.org/10.1016/j.applthermaleng.2011.01.046

[3] Wills, A.; Cruickshank, C. A.; Beausoleil-Morrison, I. 2012. Application of the ESP-r/TRNSYS Co-Simulator to Study Solar Heating with a SingleHouse Scale Seasonal Storage, Energy Procedia 30: 715-722. http://dx.doi.org/10.1016/j.egypro.2012.11.081

[4] Wallin, J.; Bastien, D.; Claesson, J. 2012. The Influence of Energy Consevation on the Performance of Solar energy Systems - A Cold Country Case Study, Energy Procedia 30: 1069-1078. http://dx.doi.org/10.1016/j.egypro.2012.11.120

[5] Biaou, A. L.; Bernier, M. A. 2008. Achieving total domestic hot water production with renewable energy, Building and Environment 43(4): 651-660. http://dx.doi.org/10.1016/j.buildenv.2006.06.032

[6] Raffenel, Y.; Fabrizio, E.; Virgone, J.; Blanco, E.; Filippi, M. 2009. Integrated solar heating systems: From initial sizing procedure to dynamic simulation, Solar energy 83(5): 657-663. http://dx.doi.org/10.1016/j.solener.2008.10.021

[7] Ampatzi, E.; Knight, I.; Wiltshire, R. 2013. The potential contribution of solar energy collection and storage systems to meeting the energy requirements of North European Housing, Solar energy 91: 402-421. http://dx.doi.org/10.1016/j.solener.2012.09.008

[8] Hobbi, A.; Siddiqui, K. 2009. Optimal design of a forced circulation solar water heating system for a residential unit in cold climate using TRNSYS, Solar energy 83(5): 700-714. http://dx.doi.org/10.1016/j.solener.2008.10.018

[9] Lund, P. D. 2005. Sizing and applicability consideations of solar combisystems, Solar energy 78(1): 59-71. http://dx.doi.org/10.1016/j.solener.2004.07.008

[10] Connolly, D.; Lund, H.; Mathiesen, B. V.; Leahy, M. 2010. A review of computer tools for analysing the integration of renewable energy into various energy systems, Applied Energy 87(4): 1059-1082. http://dx.doi.org/10.1016/j.apenergy.2009.09.026

[11] Ampatzi, E.; Knight, I. 2012. Modelling the Effect of Realistic Domestic Energy Demand Profiles and Internal Gains on the Predicted Performance of Solar energy Systems, Energy and Buildings 55: 285-298. http://dx.doi.org/10.1016/j.enbuild.2012.08.031

[12] Klein, S. A.; Beckmann, B.; Duffie, J. 2012. TRNSYS, A Transient SystemSimulation Program, Program Manual. Solar Laboratory, Madison, Wisconsin

[13] Januševičius, K.; Streckienè, G. 2013. Solar Assisted Ground Source Heat Pump Performance in Nearly Zero Energy Building in Baltic Countries, Scientific Journal of Riga Technical University. Environmental and Climate Technologies 11: 48-56.

[14] Martín, R. H.; Pérez-García, J.; García, A.; García-Soto, F. J.; López-Galiana, E. 2011. Simulation of an enhanced flat-plate solar liquid collector with wire-coil insert devices. Solar energy 85(3): 455-469. http://dx.doi.org/10.1016/j.solener.2010.12.013

[15] Lundh, M.; Zass, K.; Wilhelms, C.; Vajen, K.; Jordan, U. 2010. Influence of store dimensions and auxiliary volume configuration on the performance of medium-sized solar combisystems, Solar energy 84(7): 1095-1102. http://dx.doi.org/10.1016/j.solener.2010.03.004

[16] Jordan, U.; Furbo, S. 2005. Thermal stratification in small solar domestic storage tanks caused by draw-offs, Solar energy 78(2): 291-300. http://dx.doi.org/10.1016/j.solener.2004.09.011

[17] Terziotti, L. T.; Sweet, M. L.; McLeskey Jr., J. T. 2012. Modeling seasonal solar energy storage in a large urban residential building using TRNSYS 16, Energy and Buildings 45: 28-31. http://dx.doi.org/10.1016/j.enbuild.2011.10.023

[18] Glembin, J.; Rockendorf, G. 2012. Simulation and evaluation of stratified discharging and charging devices in combined solar energy systems, Solar energy 86(1): 407-420. http://dx.doi.org/10.1016/j.solener.2011.10.013

[19] Polysun 2000. User's manual for Polysun 3.3. SPF, Switzerland.

[20] Kalogirou, S. 2009. Solar energy Engineering: Processes and Systems. London: Academic Press. 850 p. ISBN 978-0-12-374501-9.

[21] Sorensen, B.; Breeze, P.; Suppes, G. J.; Bassam, N. E.; Silveira, S.; Yang, S.; Rosa, A. V.; Gupta, H. K.; Roy, S.; Doble, M; Broussely, M.; Maegaard, P.; Barbir, F.; Pistoia, G.; Kalogirou, S.; Storvick, T. 2009. Renewable Energy Focus Handbook, 1st Edition. Oxford: Elsevier. 528 p. ISBN 978-0-12-374705-1.

[22] energyPRO 2013. User's Guide. EMD International A/S, Denmark.

[23] Streckiené, G.; Martinaitis, V.; Andersen, A. N.; Katz, J. 2009. Feasibility of CHP-plants with thermal stores in the German spot market, Applied Energy 86(11): 2308-2316. http://dx.doi.org/10.1016/j.apenergy.2009.03.023

[24] Nielsen, S.; Möller, B. 2012. Excess heat production of future net zero energy buildings within district heating areas in Denmark, Energy 48(1): 2331. http://dx.doi.org/10.1016/j.energy.2012.04.012

[25] Šiupšinskas, G.; Adomènaitè, A. 2012. The use of solar energy for preparing domestic hot water in a multi-storey building, Science - Future of Lithuania 4(5): 507-512.

[26] Jordan, U.; Vajen, K. 2001. Influence of the DHW Load Profile on the Fractional Energy Savings: a Case Study of a Solar Combi-System with TRNSYS Simulations, Solar energy 69: 197-208. http://dx.doi.org/10.1016/S0038-092X(00)00154-7

[27] Widén, J.; Lundh, M.; Vassileva, I.; Dahlquist, E.; Ellegård, K.; Wäckelgård, E. 2009. Constructing Load Profiles for Household Electricity and Hot Water from Time-Use data-Modelling Approach and Validation, Energy and Buildings 41(7): 753-768. http://dx.doi.org/10.1016/j.enbuild.2009.02.013

[28] Axaopoulos, P. J.; Fylladitakis, E. D. 2013. Performance and economic evaluation of a hybrid photovoltaic/thermal solar system for residential applications, Energy and Buildings 65: 488-496. http://dx.doi.org/10.1016/j.enbuild.2013.06.027

[29] Schäfer, A. 2006. Efficiency test according to EN 12975-2:2006. Test report: KBT Nr. 2006-30-en. Fraunhofer Institut for Solar energy Systems. 16 p.

[30] Remund, J.; Muller, S.; Kunz, S.; Huguenin-Landl, B.; Schmid, C.; Schilter, C. 2013. Meteonorm, Global Meteorological Database, Handbook part I: Software. Bern, Switzerland.

[31] Perednis, E.; Kavaliauskas, A.; Plikšnienè, V. 2007. Investigation of hot water utilization in solar collectors, Energetics 1: 34-38.

[32] Hastings, R. S.; Wall, M. 2007. Sustainable Solar Housing: Volume I - Strategies and Solutions. London: Sterling, VA. 315 p. ISBN-13: 978-1-84407-325-2. 